\title{
EDITORIAL
}

\section{RED SOCIAL, RADIOLOGÍA Y COVID: UNA FORMA MODERNA DE COLABORAR}

\section{Felipe Castillo*}

\author{
1. Radiólogo, Unidad de Imágenes toraco-abdominales, Red de Salud UC - Christus. Santiago, Chile.
}

*Correspondencia: Felipe Castillo / fncastil@uc.cl

La pandemia por nuevo coronavirus (COVID-19) ha tomado la prioridad de consultas en Salud generando en la comunidad radiológica la necesidad de demostrar y fortalecer su rol en el análisis estandarizado y oportuno de las imágenes. Recientes recomendaciones de expertos ${ }^{(1,2)}$ nos han entregado herramientas para orientar a los equipos tratantes sobre el uso apropiado de los recursos de imagen y también comunicar la probabilidad de enfermedad por COVID-19 en aquellos pacientes en quienes se estima necesario su uso.

No obstante, lo anterior, cabe preguntarse si es que hoy en día estamos incidiendo de forma oportuna y eficaz en la mayor cantidad de pacientes posible en los que se sospecha o confirma la enfermedad, ya sea orientando a los equipos de salud en el rol de la imagen o bien asistiendo en la lectura en aquellos que se les solicita. Se suma el hecho de que en Chile un número importante de radiografías de tórax -y en menor medida tomografías computadas- no son sistemáticamente leídas ni informadas por especialistas en imagen, por lo que la utilidad de la interpretación y no de la técnica en sí, puede ser limitada.

Hoy en día, los avances tecnológicos han creado plataformas digitales de libre acceso que permiten una comunicación a distancia de forma eficiente, tal como lo es la Red Social llamada Telegram ${ }^{(3)}$, que se basa en mensajería instantánea a través de la organización de grupos que pueden superar los 1.000 miembros. Ante el conocimiento de esta plataforma, y bajo el prisma del rol social que debe ejercer nuestra especialidad, es que se inició con fecha 26 de marzo el funcionamiento de un grupo de libre acceso en esta Red destinado a centralizar las dudas de los equipos tratantes que carecen del recurso de informe radiológico a lo largo del país y resolverlas de forma oportuna.

A un mes de su creación cuenta con aproximadamente 350 miembros, en su vasta mayoría médicos generales distribuidos a lo largo de todo el país, quienes han consultado aproximadamente 50 casos clínicos. Estos se presentan en formato de viñeta clínica relevante e imágenes anonimizadas, entregándose como respuesta por parte del equipo de radiólogos informantes activos (dos a la fecha, con formación de subespecialidad en tórax) la probabilidad de COVID-19 en base a las guías existentes, probabilidad de un diagnóstico alternativo y comunicación de hallazgos incidentales.

La recepción de la iniciativa ha sido muy positiva por parte de los equipos tratantes participantes, quienes manifiestan una oportunidad de aumentar su confianza diagnóstica, guiar oportunamente el manejo de los pacientes, además de percibir una participación presente de la Radiología en estos tiempos de crisis. El grupo ha seguido en aumento en la medida que se difunde entre los equipos de salud y redes sociales.

Este es un buen ejemplo de la oportunidad que nos ofrece la tecnología para canalizar de forma centralizada los esfuerzos en aportar oportunamente como especialistas en esta pandemia, que puede servir de ejemplo para futuras iniciativas. En el advenimiento de la llamada "temporada de invierno" y consecuente circulación de nuevas infecciones, nuestra labor de especialistas será fundamental. Es una forma moderna que tenemos de colaborar y ejercer nuestro rol social ante el país de una manera simple y accesible a aquellos profesionales que requieren de nuestra opinión.

\section{Referencias}

1. Simpson S, Kay FU, Abbara S, Bhalla S, Chung JH, Chung M, et al. Radiological Society of North America Expert Consensus Statement on Reporting Chest CT Findings Related to COVID-19. Endorsed by the Society of Thoracic Radiology, the American College of Radiology, and RSNA. Radiol Cardiothorac Imaging. 2020 Mar 25; 2(2): e200152. Disponible en: https://doi.org/10.1148/ryct.2020200152.

2. Rubin GD, Ryerson CJ, Haramati LB, Sverzellati N, Kanne JP, Raoof S, et al. The Role of Chest Imaging in Patient Management during the COVID-19 Pandemic: A Multinational Consensus Statement from the Fleischner Society. Radiology [Internet]. 2020 Apr 7; 296(1): 172-180. Disponible en: https://doi.org/10.1148/radiol.2020201365.

3. Telegram Messenger (citación 23 abril 2020). Disponible en: https://telegram.org. 